Article

\title{
A Remote Sensing Based Integrated Approach to Quantify the Impact of Fluvial and Pluvial Flooding in an Urban Catchment
}

\author{
Manoranjan Muthusamy ${ }^{1}\left(\mathbb{0}\right.$, Monica Rivas Casado ${ }^{1, *}{ }^{\mathbb{C}}$, Gloria Salmoral ${ }^{1}$, Tracy Irvine ${ }^{2}$ and \\ Paul Leinster ${ }^{1}$ \\ 1 School of Water, Energy and Environment, Cranfield University, College Road, Cranfield, \\ Bedfordshire MK43 0AL, UK; manoranjan.muthusamy@cranfield.ac.uk (M.M.); \\ gloria.salmoral@cranfield.ac.uk (G.S.); paul.leinster@cranfield.ac.uk (P.L.) \\ 2 Oasis Hub, 3rd Floor 40 Bermondsey Street, London SE1 3UD, UK; tracy.irvine@oasishub.co \\ * Correspondence: m.rivas-casado@cranfield.ac.uk; Tel.: +44-012-347-50111
}

Received: 31 January 2019; Accepted: 4 March 2019; Published: 8 March 2019

\begin{abstract}
Pluvial (surface water) flooding is often the cause of significant flood damage in urban areas. However, pluvial flooding is often overlooked in catchments which are historically known for fluvial floods. In this study, we present a conceptual remote sensing based integrated approach to enhance current practice in the estimation of flood extent and damage and characterise the spatial distribution of pluvial and fluvial flooding. Cockermouth, a town which is highly prone to flooding, was selected as a study site. The flood event caused by named storm Desmond in 2015 (5-6/12/2015) was selected for this study. A high resolution digital elevation model (DEM) was produced from a composite digital surface model (DSM) and a digital terrain model (DTM) obtained from the Environment Agency. Using this DEM, a 2D flood model was developed in HEC-RAS (v5) 2D for the study site. Simulations were carried out with and without pluvial flooding. Calibrated models were then used to compare the fluvial and combined (pluvial and fluvial) flood damage areas for different land use types. The number of residential properties affected by both fluvial and combined flooding was compared using a combination of modelled results and data collected from Unmanned Aircraft Systems (UAS). As far as the authors are aware, this is the first time that remote sensing data, hydrological modelling and flood damage data at a property level have been combined to differentiate between the extent of flooding and damage caused by fluvial and pluvial flooding in the same event. Results show that the contribution of pluvial flooding should not be ignored, even in a catchment where fluvial flooding is the major cause of the flood damages. Although the additional flood depths caused by the pluvial contribution were lower than the fluvial flood depths, the affected area is still significant. Pluvial flooding increased the overall number of affected properties by $25 \%$. In addition, it increased the flood depths in a number of properties that were identified as being affected by fluvial flooding, in some cases by more than 50\%. These findings show the importance of taking pluvial flooding into consideration in flood management practices. Further, most of the data used in this study was obtained via remote sensing methods, including UAS. This demonstrates the merit of developing a remote sensing based framework to enhance current practices in the estimation of both flood extent and damage.
\end{abstract}

Keywords: fluvial flooding; pluvial flooding; HEC-RAS; remote sensing; unmanned aircraft system; flood impact; urban catchment 


\section{Introduction}

Flood events in England are estimated to cause damage losses to residential and non-residential properties of more than $£ 1$ billion pounds annually (2008 values) [1]. Flooding that affects properties arises from different sources including coastal, fluvial and pluvial. Coastal flooding is the result of the combined effect of high tides and storm events. Fluvial flooding occurs as a result of water overtopping the river banks when the channel cannot cope with the water draining into it, whilst pluvial flooding occurs as a result of heavy rainfall overwhelming the drainage capacity of a local area [1]. Across England, the Environment Agency (EA) estimates that there are 2.7 million properties at risk of fluvial and coastal flooding, three million properties at risk of pluvial flooding and 660,000 at risk from all sources (coastal, fluvial and pluvial) [1]. Historically, more focus has been given to coastal and fluvial flooding in flood risk management and mitigation with a particular emphasis on river catchment and flood plain management [2,3]. Consequently, considerable effort has been invested in damage data collection, data analysis and model development to investigate coastal and fluvial floods.

The cost of repairing a house after flooding is typically in the range of $£ 10,000$ and $£ 50,000$ depending upon flood depth and the type of property [4]. Damage losses associated with fluvial flooding include domestic clean-up, household contents damage, building fabric damage and the provision of alternative accommodation [5,6]. Multiple studies have focused on quantifying the effect of fluvial flooding [7-9]. However, only a few studies have focused on assessment of damage due to pluvial flooding alone. One of the reasons for this is the complexity of the flooding processes in urban areas and the associated difficulties of source apportionment, the need for high resolution data, and the larger number of stakeholders involved [2]. To the authors' knowledge, only the works by [10-12] have looked at quantifying the economic damage of pluvial flooding. Among these studies, [11] also pointed out that current flood management and insurance practices generally fail to take into account the combined effect of pluvial and fluvial modelling. Rather, most of the attention is paid to fluvial flooding.

Currently, less is known about the modelling and estimation of pluvial flood risk and its effective management and mitigation. In addition, the contribution of pluvial flooding during what is considered to be a fluvial event is often not considered. This restricted knowledge about the extent and impact of pluvial flooding and its consistent underestimation have translated into uninformed and biased predictions of the spatiotemporal occurrence of flooding within urban environments [11]. For example, the serious flooding that was experienced in Cockermouth (Cumbria, UK) in 2015-2016 was considered at the time to be a fluvial event [10]. The overall household damage costs were estimated to be $£ 10$ million, assuming no resistance measures were in place. Upon further analysis, it was found [13] that pluvial flooding was responsible for an estimated $£ 3.6$ million of the total household flood impact costs of $£ 10$ million.

Although significant resources have been invested in the past decade to improve existing pluvial models, pluvial flood predictions are still in the relatively early stages of development for urban environments. This can mean that there is a difficulty in interpreting the contribution from the various sources of flooding during an event and a mismatch between the observed number and location of properties impacted during a flood event and flood risk maps that have been predominately based on fluvial or coastal flooding.

The different accountabilities and responsibilities for fluvial and pluvial flooding also add to the complexity of providing effective flood risk management measures. In England, fluvial flooding from main rivers and critical ordinary watercourses is the responsibility of the EA whilst surface water flooding and flooding from ordinary water courses is the responsibility of the relevant local authority [1]. The history and the accountabilities mean that there is a greater level of modelling, monitoring and scheme development focused on fluvial and coastal flooding risks than on pluvial flooding risks. There is, therefore, a need to improve our current knowledge of the extent and impact of pluvial flooding in urban areas and how the risks can best be reduced. 
Flood extent and depth, regardless of the source of the flooding, are almost always predicted from numerical modelling. These models can be broadly categorised into 1D river/sewer network models [14,15] and 2D surface models [16,17]. Either a single model or a combination of these models (1D and 2D coupling, e.g., [18,19]) is employed to predict the flood extent and depth. A 2D model typically requires remote sensing input data, primarily comprising digital surface models (DSMs) and/or digital terrain models (DTMs). The resolution of such products can vary from scales finer than $250 \mathrm{~m}$ to scales coarser than $1 \mathrm{~km}$ [20-22]. In most cases, the accuracy and detail (resolution) of flood predictions depend upon the resolution of the digital elevation model (DEM) used to obtain the flood estimates [20-22]. Usually, due to the coarser resolution of the products, DEM based models over-predict the likely flood extent [22].

The increased availability of various remote sensing technologies over the last decade has made environmental data collection and modelling less challenging [23-25]. For example, the increased availability of high-resolution DEMs over the last decade has made the implementation of 2D models much easier than it used to be [26,27]. Consequently, a number of 2D flood inundation models have been developed and widely used. These include MIKE [28], InfoWorks [29] and HEC-RAS [30] which are capable of simulating both pluvial and fluvial floods. However, even with the increase of high resolution DEMs and 2D modelling tools, there continues to be less focus on pluvial modelling compared with fluvial [2]. For example, the Surface Water Flooding Hazard Impact Model (SWF HIM) is being trialled across England and Wales, by the Flood Forecasting Centre to determine the extent and severity of pluvial flooding at a scale of $1 \mathrm{~km} \times 1 \mathrm{~km}$. Validation of SWF HIM to date has only been undertaken via a verification analysis based on flood impact observation data obtained from media sources [31]. Some studies in the UK have used the reported incidence of household flooding to calibrate the pluvial flood extents [32,33]. However, only using household reports will not provide a comprehensive calibration. There is, therefore, a need to increase the current knowledge base to improve the prediction of the extent and impact of pluvial flooding.

In recent years, unmanned aircraft systems (UASs), commonly known as drones, have been used to provide a detailed (high resolution) topographical characterisation of urban areas pre- and post-flood events [13]. The potential of UASs to detect properties impacted by flooding (pluvial and fluvial) has been demonstrated in [13], where features (e.g., natural debris, scour, rubble, exposed mains) indicating flood impact were identified from high resolution $(3 \mathrm{~cm})$ aerial imagery captured with a UAS and used to detect which properties had been affected by flooding. Here, we build on the work presented in [13] contributing to the current knowledge base of the extent and impact of pluvial flooding using a 2D flood surface model. In this study, we present a comprehensive remote sensing based integrated methodology to quantify the impacts of both fluvial and pluvial flooding in a single event using remote sensing data. This will be achieved through the following objectives:

1. To model the spatial distribution of pluvial and fluvial flooding using a high-resolution DEM based 2D model for the study site of Cockermouth.

2. To compare the flood extent and damage for different land use types between pluvial and fluvial flooding.

3. To estimate the number of residential properties affected by pluvial and fluvial flooding using a combination of model results and UAS data collection.

\section{Methodology}

\subsection{Study Site and Selected Flood Event}

The study site covers 142 ha in the market town of Cockermouth (Alledarle, Cumbria, UK) at the confluence of the rivers Cocker and Derwent (Figure 1). The river Cocker is a tributary of the Derwent and flows for $19 \mathrm{~km}$ before joining the Derwent in Cockermouth. The town has a population of around 8800 people and 4000 households (2011) [34]. The area has been affected multiple times by flooding within recent decades. In 2015, the study site was affected by three consecutive storms: Desmond 
(5-6/12/2015), Eva (24/12/2015) and Frank (29-30/12/2015) [35]. Storm Desmond was the largest in magnitude on record, with the flood event affecting a total of 466 properties [36] as a result of $300 \mathrm{~mm}$ of rain falling over a $24 \mathrm{~h}$ period [36] and flows of $395 \mathrm{~m}^{3} \mathrm{~s}^{-1}$ being measured in the river Derwent at the Ouse Bridge gauging station [37] and $170 \mathrm{~m}^{3} \mathrm{~s}^{-1}$ on the river Cocker at the Southwaite bridge gauging station [38]. The estimated annual exceedance probability for the rainfall event was less than $0.01 \%$ and less than $1 \%$ for the recorded discharge values. The storm generated wind gusts of up to $81 \mathrm{mph}$ and impacted 5200 properties across Cumbria and Lancanshire [39].

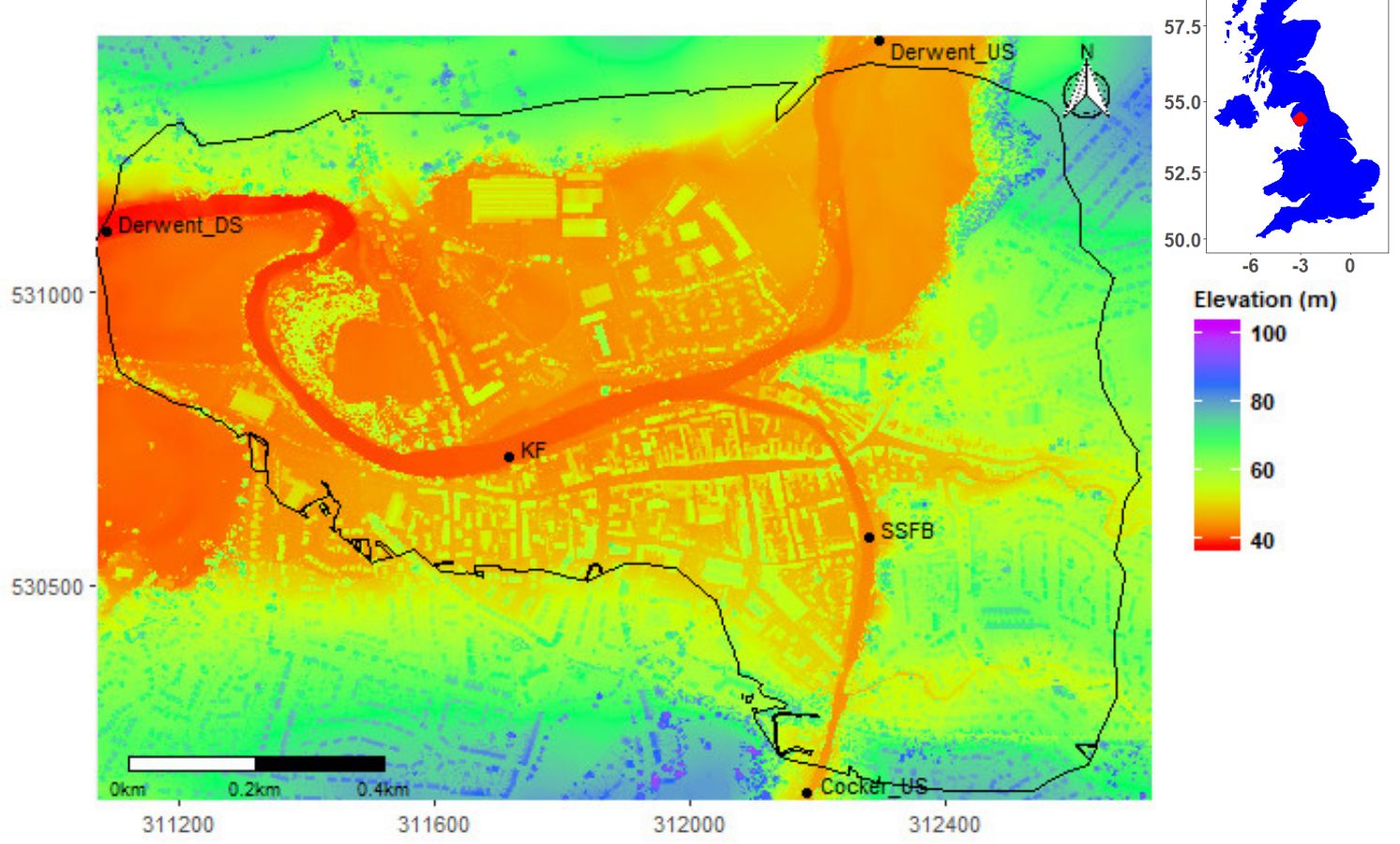

Figure 1. Digital Elevation Model (DEM) of the study site (Cockermouth, Allerdale, Cumbria, UK). Data collected by the EA in 2015; DEM derived from photogrammetry techniques applied to aerial imagery collected from aircraft. The abbreviations within the map show the locations of the river boundaries used in the hydrological model for the river Derwent upstream (Derwent_US) and downstream (Derwent_DS) and the river Cocker (Cocker_US), the Kingfisher (KF) gauging station [40] along the river Derwent and the South Street Footbridge (SSFB) gauging station [41] along the river Cocker. The black outline shows the area covered for UAS data collection. The elevation is presented in meters above ordnance datum (AOD).

\subsection{Data Collection and Collation}

Figure 2 summarises the entire workflow of the studies and the following sections describe the workflow in detail. The workflow includes UAS data collection, topographical and hydrological data collation, photogrammetric analysis, flood inundation modelling as well as flood extent and impact estimation.

\subsubsection{UAS Data}

A Sirius-Pro (Topcon Positioning System Inc., California, US) fixed wing platform was deployed $(13 / 12 / 15)$ over the study site to collect high resolution aerial imagery in the visible spectrum (Figure 2). The Sirius-Pro platform enabled collection of the imagery under the rainy and gusty conditions (up to $65 \mathrm{~km} \mathrm{~h}^{-1}$ ) present after storm Desmond. The key characteristics of the platform are summarized in 
Table 1. The UAS platform incorporated a 16-megapixel Panasonic GX-1 on-board camera (30 mm pixel size, $14 \mathrm{~mm}$ focal length, Micro 4/3 sensor type) automatically triggered at pre-programmed way points to enable data collection. The flight plan required multi-passes with an imagery overlap of $85 \%$ along and $65 \%$ across the track. The flight height was constant and set up to $112 \mathrm{~m}$, this providing a ground sampling distance of $0.026 \mathrm{~m}$. Further details about the data collection procedure can be found in [13]. All data were collected following the Civil Aviation Authority (CAA) regulation CAP 722 [42] and CAP 393 [43] at all times by a fully qualified Remote Pilot Qualification-small (RPQs) pilot and with a special CAA permission for emergency response that enabled flights over congested areas beyond the visual line of sight (BVLOS) up to $1000 \mathrm{~m}$. Data collection was carried out with surface wind speeds between $2.6 \mathrm{~m} \mathrm{~s}^{-1}$ and $3.6 \mathrm{~m} \mathrm{~s}^{-1}$ and directions varying from $50^{\circ}$ to $250^{\circ}$, with prevailing visibility obscure and weather conditions ranging from fog to light rain/drizzle (Spadeadam meteorological aerodrome report [44]). Six ground control points (GCPs) randomly distributed within the study site were used for georeferencing purposes. The distribution of GCPs was planned to optimize spatial coverage and was subject to access constraints. A Topcon HiPer V GPS (Topcon Positioning System Inc., California, US) was used to obtain the location of the GCP centroids.

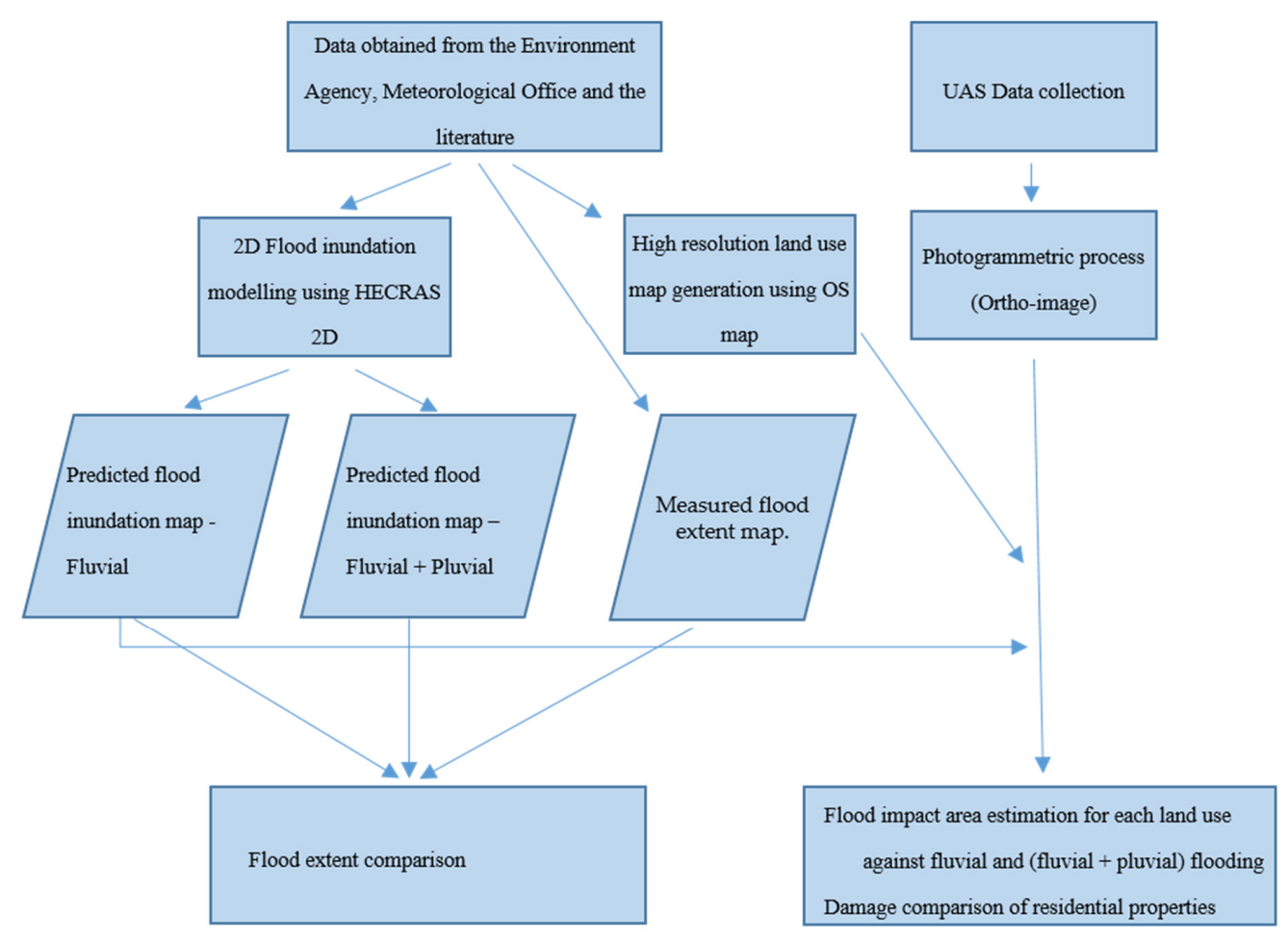

Figure 2. Diagram showing the work flow with the key steps followed in this study.

Table 1. Summary of the characteristics of the Sirius-Pro (Topcon Positioning System Inc., California, US) fixed wing platform used to collect high-resolution aerial imagery over the study site (Cockermouth, Cumbria, UK) (13/12/2015) after storm Desmond (5-6/12/2015).

\begin{tabular}{cc}
\hline Parameter & Value \\
\hline Wingspan & $163 \mathrm{~cm}$ \\
Length & $120 \mathrm{~cm}$ \\
Lippo battery (30 C, 18.5 V) & $5300 \mathrm{mAh}$ \\
Flight endurance & $50 \mathrm{~min}$ \\
GPS & GNSS-RTK - L1 $/$ L 2 GPS, GLONASS with RTK \\
GPS accuracy (planimetry) & $0.01 \mathrm{~cm}$ \\
GPS accuracy (altimetry) & $0.015 \mathrm{~cm}$ \\
IMU & $9 \mathrm{DOF}$ \\
Take payload & $2.7 \mathrm{~kg}$ \\
\hline
\end{tabular}




\subsubsection{Topographical and Hydrological data}

The DSM and the DTM were generated using a composite dataset comprised of the most detailed up to date data available for each location throughout the period of 2010-2015 by the EA. These data were collected by the EA using a Light Detection and Ranging (LiDAR) sensor. Up to 100,000 measurements per second were made of the ground, allowing highly detailed terrain models to be generated at spatial resolutions of between $25 \mathrm{~cm}$ and $2 \mathrm{~m}$ with the vertical accuracy of $+/-15 \mathrm{~cm}$ root mean square error (RMSE) [45]. In this study, we selected $1 \mathrm{~m}$ resolution taking into account the level of detail required and the corresponding simulation time. The OS MasterMap Topography Layer (Ordnance Survey, Southampton, UK) was used to identify the land use within the study site. The publication date of the OS MasterMap Layer was 30/01/17 with an extraction date of 12/01/17.

The upstream river boundary conditions (i.e., river water levels) for both the river Cocker and the river Derwent at a $1 \mathrm{~h}$ temporal resolution were also provided by the EA for the period between 03/12/15 and 09/12/15. An ancillary data set was also provided by the EA with (i) the measured river water levels and discharge data for the river Cocker at Southwaite bridge [38] and the river Derwent at the Ouse bridge [37] for the period 03/12/15-09/12/15 at a temporal resolution of $15 \mathrm{~min}$, (ii) the measured river water levels at the Kingfisher (KF) (Derwent) [40] and the South Street Foot Bridge (SSFB) (Cocker) (Figure 1) [41] gauging stations for the period 03/12/15-09/12/15 at a temporal resolution of $15 \mathrm{~min}$, and (iii) the observed flood extent for the event. Hourly rainfall data measured at the nearest rain gauge station (Bridgefoot, Allerdale, Cumbria, UK) for the period 03/12/15-09/12/15 was obtained from MetOffice.

\subsubsection{Flood Impact}

The residential properties that were affected by flooding, regardless of flood type, were identified from the orthoimage generated from the UAS data. For that purpose, features indicating flood impact (i.e., bin bags, natural debris, exposed mains, scour, skip, water-damaged goods, remaining water, compromised bridge access and dehumidifiers ) were visually identified following the methodology described in [46-48]. Residential properties in close proximity to flood impact features were assumed to be impacted by flooding. Residential properties were distinguished from any other property types via direct on-site observations. A more detailed description of the methodology can be found in [13].

\subsection{Photogrammetric Analysis}

The imagery was processed with Photoscan Pro version 1.1.6 (Agisoft LLC, St. Petersburg, Russia). Only the images that met specific quality criteria (i.e., spatial coverage, overlap and image quality) were used in the photogrammetric process to generate an orthoimage for the study site. The location of the six GCPs was used to locate, translate and rotate (i.e., georeference) the individual frames into the World Geodetic System WGS84, minimizing distortion. The coregistration error was automatically derived from Photoscan Agisoft for $x, y$ and $z$ as follows:

$$
R M S E=\sqrt{\frac{\sum_{j=1}^{N}\left[\left(\hat{x}_{j}-x_{j}\right)^{2}+\left(\hat{y}_{j}-y_{j}\right)^{2}+\left(\hat{z_{j}}-z_{j}\right)^{2}\right]}{N}}
$$

where RMSE is the Root Mean Square Error; $\hat{x}, \hat{y}$ and $\hat{z}$ are the image derived coordinates at location $j$; $x, y$ and $z$ are the associated RTK GPS positions of the GCPs, and $N$ is the total number of GCPs.

The geomatic products generated from a total of 1879 frames required $36 \mathrm{~h}$ of processing time on a computer with an Intel Core i7-5960k $3.30 \mathrm{GHz}$ processor, $64 \mathrm{~GB}$ RAM, and a Geforce Titan X Graphics card. The coregistration error was $0.038 \mathrm{~m}$ in $\mathrm{X}, 0.121 \mathrm{~m}$ in $\mathrm{Y}$ and $0.120 \mathrm{~m}$ in $\mathrm{Z}$ and an overall RMSE of $0.02 \mathrm{~m}$. 


\subsection{Flood Inundation Modelling}

The 2D flood inundation modelling was carried out using HEC-RAS (v5) 2D [30]. HEC-RAS 2D is capable of simulating surface flooding caused by rainfall as well as river flooding [49]. HEC-RAS 2D solves either the full 2D Saint Venant equations (Equation (2)) or the 2D diffusive wave equations (Equations (3) and (4)) [50] described below:

$$
\begin{gathered}
\frac{\partial \zeta}{\partial x}+\frac{\partial p}{\partial x}+\frac{\partial q}{\partial x}=0 \\
\frac{\partial p}{\partial t}+\frac{\partial}{\partial x}\left(\frac{p^{2}}{h}\right)+\frac{\partial}{\partial y}\left(\frac{p q}{h}\right)=-\frac{n^{2} p g \sqrt{p^{2}+q^{2}}}{h^{2}}-g h \frac{\partial \zeta}{\partial x}+p f+\frac{\partial}{\rho \partial x}\left(h \tau_{x x}\right)+\frac{\partial}{\rho \partial y}\left(h \tau_{x y}\right) \\
\frac{\partial q}{\partial t}+\frac{\partial}{\partial y}\left(\frac{q^{2}}{h}\right)+\frac{\partial}{\partial x}\left(\frac{p q}{h}\right)=-\frac{n^{2} q g \sqrt{p^{2}+q^{2}}}{h^{2}}-g h \frac{\partial \zeta}{\partial y}+q f+\frac{\partial}{\rho \partial y}\left(h \tau_{y y}\right)+\frac{\partial}{\rho \partial x}\left(h \tau_{x y}\right)
\end{gathered}
$$

where $h$ is the water depth (m), $p$ and $q$ are the specific flow in the $x$ and $y$ directions $\left(\mathrm{m}^{3} \mathrm{~s}^{-1}\right)$, is the surface elevation (m), $g$ is the acceleration due to gravity $\left(\mathrm{m} \mathrm{s}^{-2}\right), n$ is the Manning resistance, $\rho$ is the water density $\left(\mathrm{kg} \mathrm{m}^{-3}\right), \tau_{x x}, \tau_{y y}$ and $\tau_{x y}$ are the components of the effective shear stress and $f$ is the Coriolis $\left(\mathrm{s}^{-1}\right)$. When the diffusive wave is selected the inertial terms of the momentum equations (Equations (3) and (4)) are neglected.

The main inputs for HEC-RAS 2D are the DEM, rainfall data and the boundary conditions. A DEM of the study site at $1 \mathrm{~m}$ resolution was generated using the DSM and DTM obtained from the EA; the rivers were extracted from the DTM and replaced in the DSM to obtain the river depths. The resulting DEM is presented in Figure 1. Upstream river boundary conditions for both the river Cocker and the Derwent were obtained from the EA at $15 \mathrm{~min}$ temporal resolution. However, the nearest measurement locations are located at Southwaite Bridge for River Cocker and Ouse bridge for the river Derwent. These locations are considerably farther from the river boundaries (Cocker_US and Derwent_US in Figure 1) used in this study. Considering the amount of data and time needed to model the entire extent using these boundaries and also considering the focus of this study, it was not feasible to model the entire extent. Instead, the data obtained at the gauging stations of SSFB and KF (Figure 1) were used to estimate the discharge time series at the upstream boundaries located at the Southwaite bridge (Cocker) and the Ouse bridge (Derwent). First, the discharge boundary data available for the Southwaite bridge and Ouse bridge were used for the boundaries at locations Cocker_US and Derwent_US (Figure 1), respectively. The water levels at locations SSFB and KF were then extracted from the modelled results and compared against the observed water level data provided by the EA for these locations. Finally, the boundary conditions were readjusted until the simulated water levels and observed water levels at locations SSFB and KF matched (Figure 3).

HEC-RAS 2D was used to model the effect of the fluvial flooding as well as the combined effect of both fluvial and pluvial flooding. In the first instance, no rainfall data was used to obtain the modelled results. In the second case, the hourly rainfall data measured at Bridgefoot (Allerdale, Cumbria, UK) was also used for the simulations in addition to the boundary conditions set for fluvial flooding. Since HEC-RAS 2D requires the effective rainfall, infiltration and drainage effects must be removed from the measured rainfall [30]. First, a rainfall reduction of $12 \mathrm{~mm} \mathrm{hr}^{-1}$ was used to account for reduction by drainage. This representative value is suggested by the EA and was found to be applicable to most of the urban catchments in the UK [50]. In addition, a runoff coefficient of $70 \%$ was chosen to represent the effect of infiltration as suggested by the EA [50]. The model was run to provide outputs for all the runs considered from $04 / 12 / 15$ to $08 / 12 / 15$.

\subsection{Flood Extent and Impact}

The extent and impact of the modelled flood event were estimated for both fluvial flooding and fluvial and pluvial flooding combined. Both the extent and impact of pluvial flooding were calculated 
as the difference between the modelled results of the fluvial and the combined effects. The flood extents of both pluvial and combined sources were visually compared with the flood extent provided by the EA for the studied event.

The area affected by flooding was calculated for each of the three categories (fluvial, pluvial and combined) identified by the use of the OS MasterMap (Ordnance Survey, Southampton, UK) (i.e., buildings, roads, and bare land). The maximum flood depth during the event was estimated for each of the multiple land use polygons. The impact was measured as the number of residential properties flooded. Only those properties identified as being affected in both the flood modelled outputs and the UAS imagery were considered to be impacted by flooding.

\section{Results}

\subsection{Flood Extent}

Figure 3 shows the simulated water levels and the measured water levels at locations SSFB and KF (Figure 1). The model prediction error was estimated as the difference between the predicted and observed values at locations SSFB and KF and RMSE) is presented in Table 2. There is a better calibration at SSFB (RMSE of $0.28 \mathrm{~m}$ ) as there is only one boundary (Cocker_US) that has to be adjusted to obtain a better calibration, whereas water levels at KF were calibrated by adjusting boundary conditions at both Cocker_US and Derwent_US resulting in a weaker calibration overall (RMSE of $0.69 \mathrm{~m}$ ). It should be noted that during the calibration of water levels, the prediction of peak water levels was the priority as further analyses were carried out using the maximum flood inundation depths caused by peak water levels. Consequently, peak flows were well calibrated with $94 \%$ and $99 \%$ accuracy at SSFB and KF respectively.

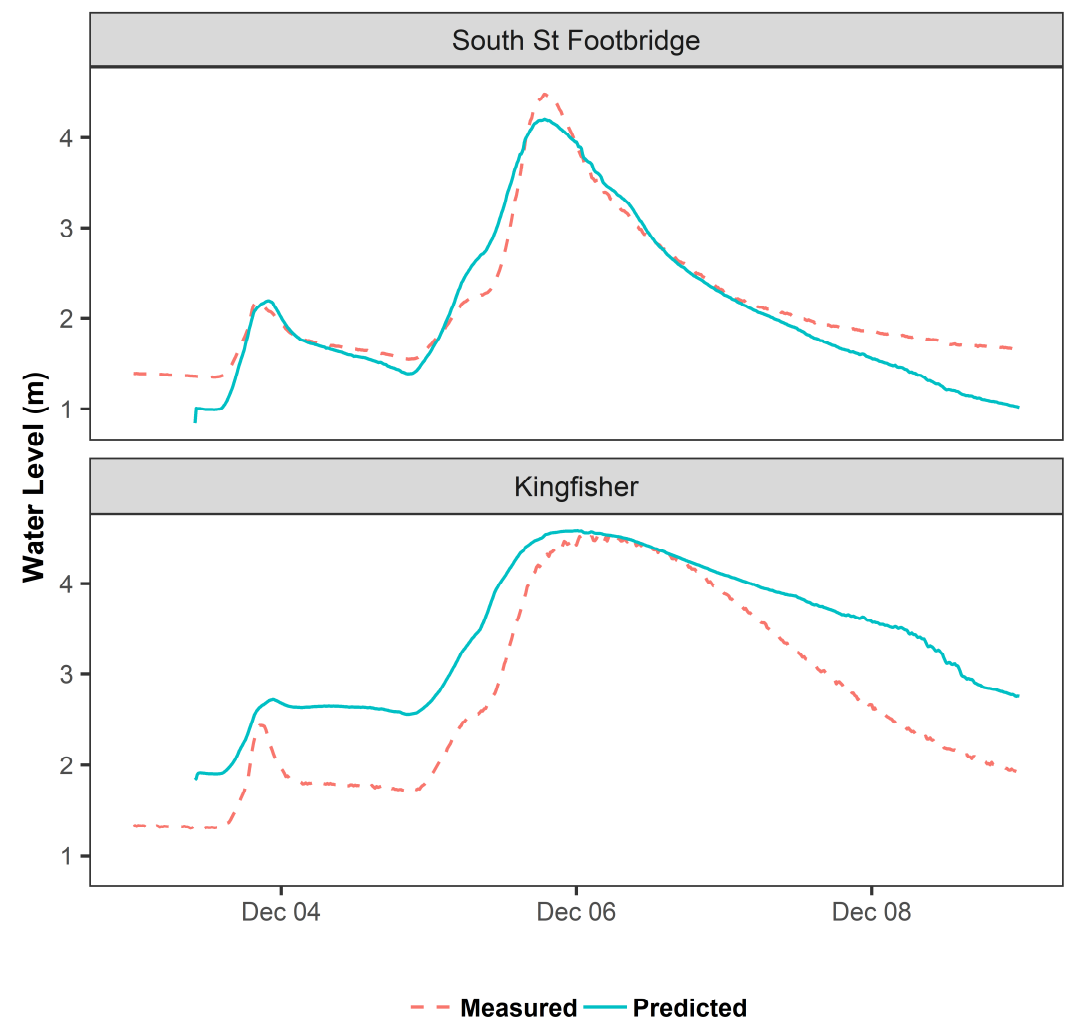

Figure 3. Measured and predicted water levels at two gauging locations within the study site: South Street Footbridge (SSFB, the river Cocker) and Kingfisher (KF, the river Derwent). The model used was HEC-RAS (v5) 2D [30]. 
Table 2. Root mean square error (RMSE) and percentage error in the prediction of the peak flow at the locations selected for model calibration. The model used was HEC-RAS (v5) 2D [30]. SSFB and KF stand for South Street Footbridge and Kingfisher, respectively.

\begin{tabular}{ccc}
\hline & SSFB & KF \\
\hline RMSE $(\mathrm{m})$ & 0.28 & 0.69 \\
Percentage error in the prediction of peak flow & $6 \%$ & $1 \%$ \\
\hline
\end{tabular}

Three flood inundation extent maps are presented in Figure 4. Figure 4a shows the measured flood extent provided by the EA. Figure $4 b$,c present the maximum flood extent derived from the model results for fluvial and combined sources (i.e., pluvial + fluvial) respectively. The fluvial model outputs presented here in general accord well with the EA flood extents presented on their flood extent maps with a slight discrepancy highlighted by a red box in Figure 4. This difference could be due to the use of temporary flood barriers such as sand bags that could not be considered in the DEM used for the model. For example, the EA reported [36] that at some locations temporary barrier was used (e.g. sand bags) as the flood spread which cannot be accurately represented in a fixed DEM. It should also be noted that the EA flood extent was provided with a note stating that not all the areas within the outline extent were flooded. However, no further information was available to identify the areas within the extent that were not flooded. Also, the complete area of any building that was affected by flood indicated as flooded in the EA flood extent map, unlike in the fluvial map where even within a building the flood extent was limited based on the height of the flood level. This explains why the EA flood extent is completely filled whereas the fluvial model extent contains many unflooded areas. However, the outer boundary of the extents are almost similar.
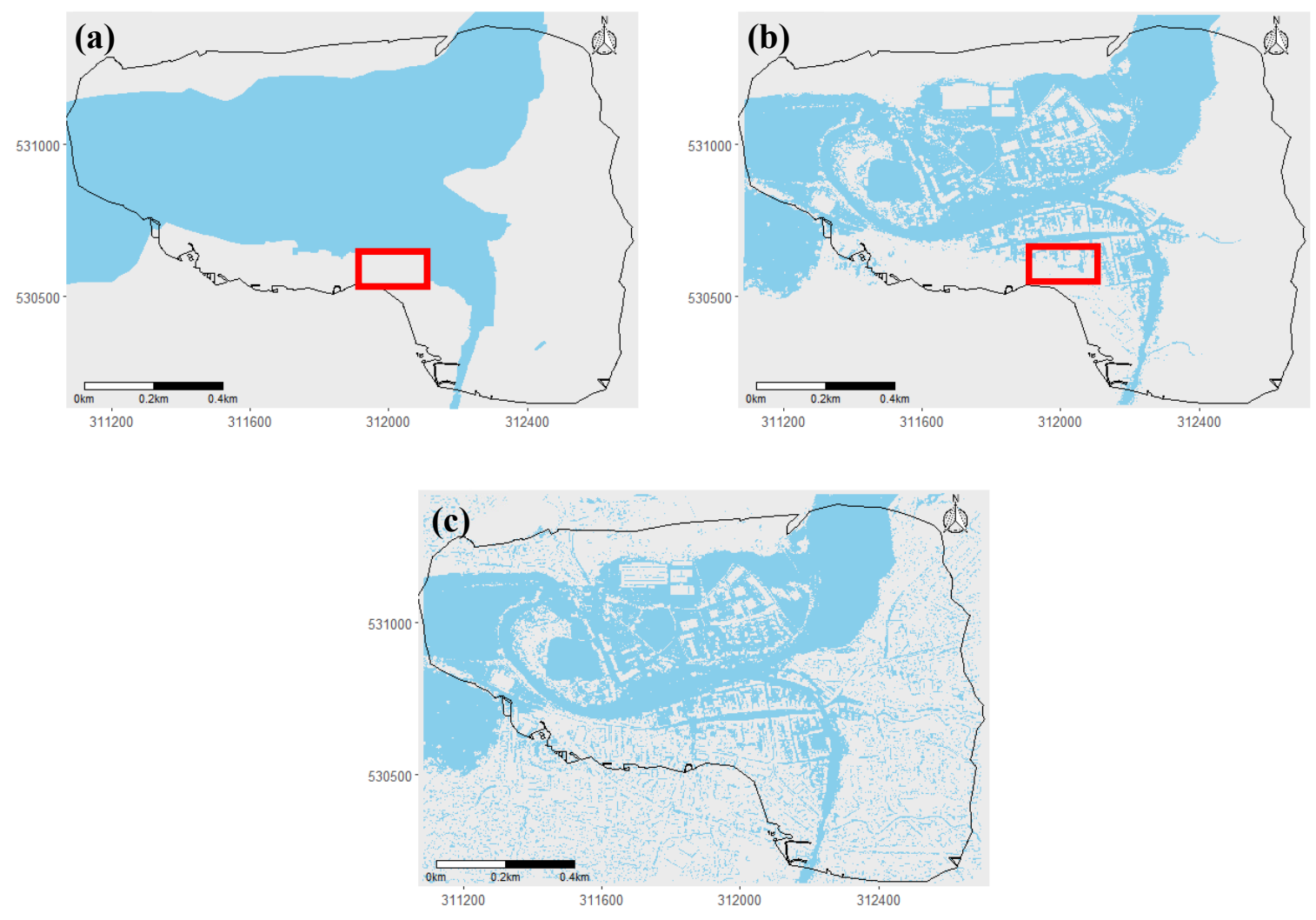

Figure 4. (a) Flood extent provided by the EA (EA) representing the full extent of the floods after storm Desmond (5-6/12/15). (b) Fluvial flood extent derived from HEC-RAS (v5) 2D [30]. (c) Combined (fluvial and pluvial) flood extent derived from HEC-RAS 2D. The red box highlights the differences identified between the EA and the fluvial modelled flood extent. 


\subsection{Flood Impact}

The extent of the combined flood in Figure $4 \mathrm{c}$ shows that there are many areas that are affected by pluvial flooding. However, most of these flood depths are less than $0.1 \mathrm{~m}$. Figure 5 shows the different land use types identified using OS data within the study site. Figure 6 shows the flood depth (average depth over each polygon) map for fluvial flooding and combined flooding for the extent defined in Figure 5. As already seen in Figure 4, the flooding in Cockermouth was a result of a combination of fluvial and pluvial flooding. The combined flood extent, therefore, covers a greater area of land than that indicated by the fluvial flooding alone. The pluvial flood depths were mostly less than $1 \mathrm{~m}$. The greater flood depths are mostly caused by the fluvial flooding or where the pluvial flooding is added to the overall flood depth. To explore this further we calculated the contribution of the pluvial flood in the total flooded area for specific flood depth thresholds and for each land use type (Figure 7). Half of the building area ( $\sim 0.8 \mathrm{ha}$ ) that is flooded up to $0.1 \mathrm{~m}$ is due to the addition of pluvial flooding whilst more than 1 ha of road area is flooded up to $0.1 \mathrm{~m}$ due to the addition of pluvial flooding. Pluvial flooding also affected 4 ha of bare land. The bare land flooding needs to be taken into account in urban planning decisions to avoid building in areas prone to flooding. It can also inform the design of sustainable drainage systems (SuDS).

The summary of affected residential properties and the contribution from each flood type is presented in Table 3. Out of the 213 affected residential properties, only 162 were identified when the fluvial flooding was considered alone. Not only does the pluvial flooding increase the number of affected properties by 51, it also increased the flood depths in 146 of the properties that were identified as being affected by fluvial flooding. In 21 of the properties, the pluvial flooding increased the flood depth by more than $50 \%$. There are places where the pluvial contribution, even when it is low, could have resulted in flood water entering properties.

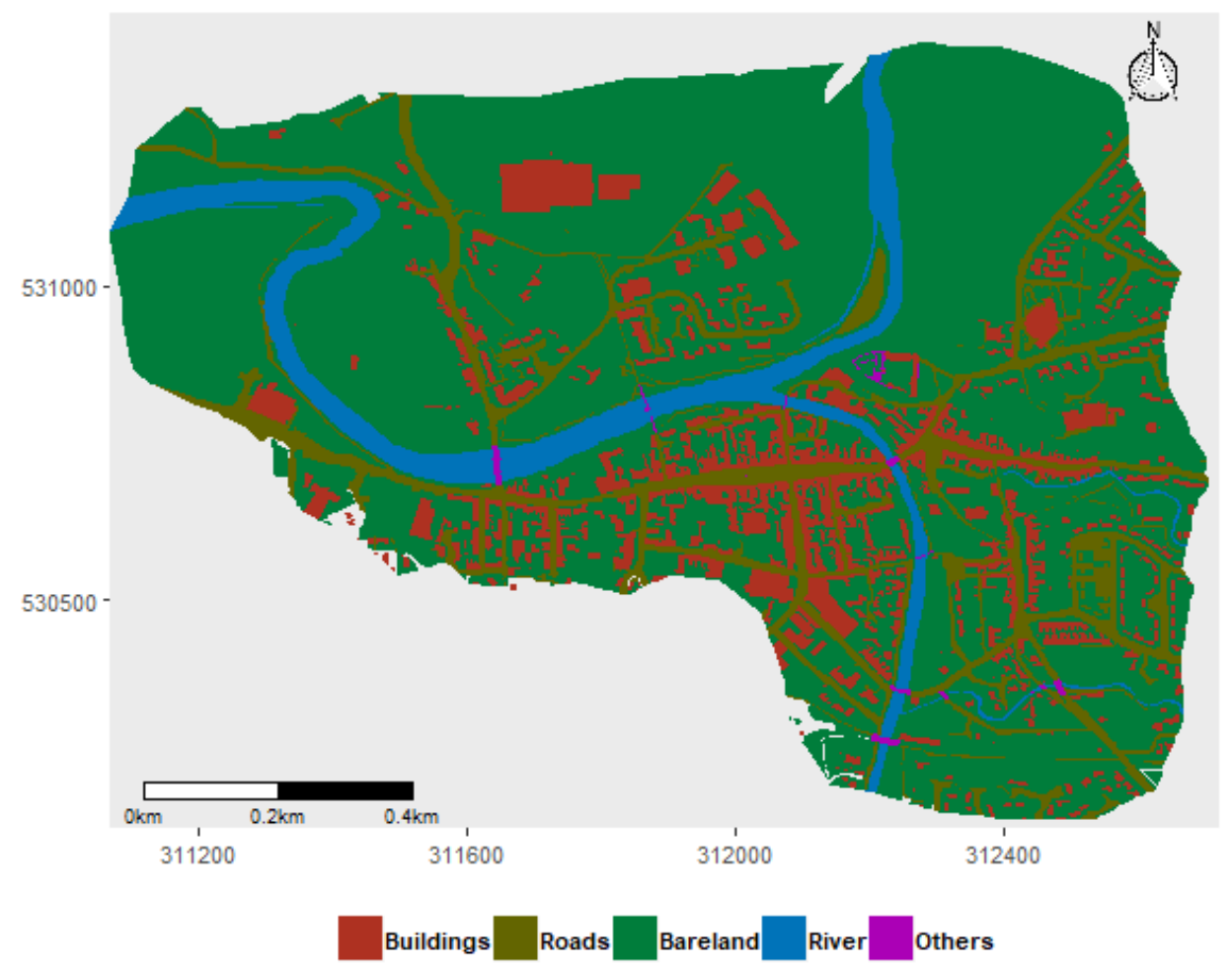

Figure 5. Land use classification of the study site (Cockermouth, Allerdale, Cumbria, UK). Contains OS data $\odot$ Crown Copyright and database. 


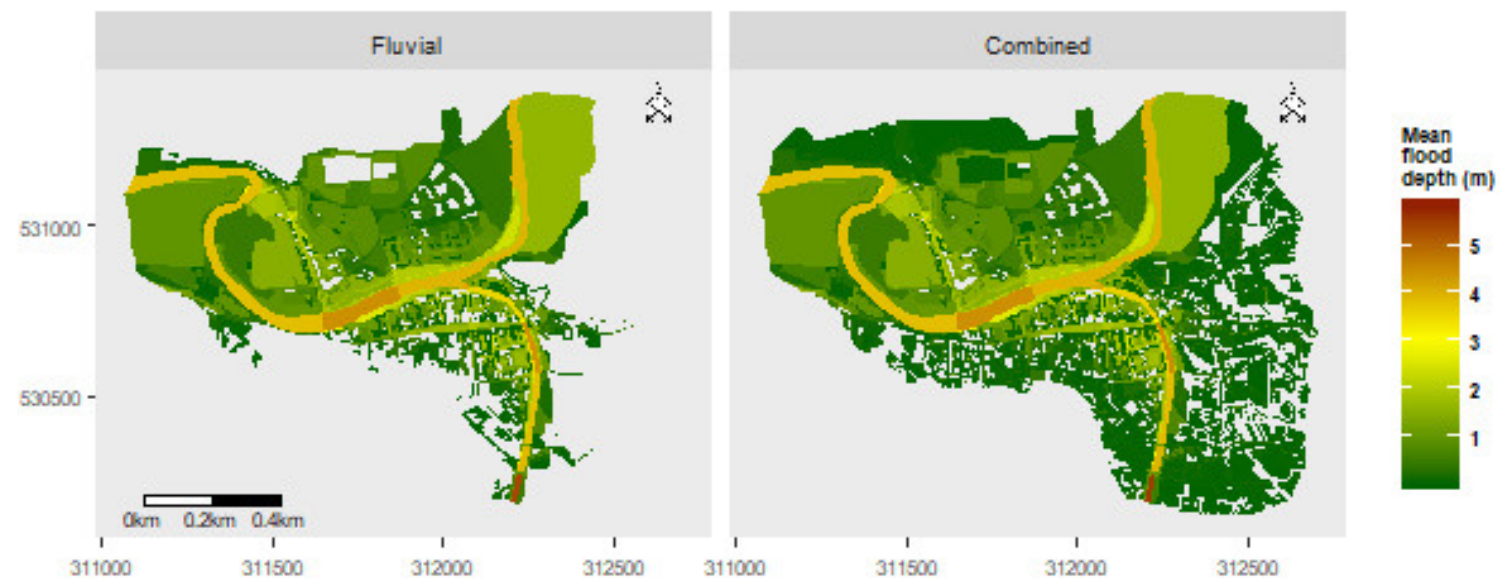

Figure 6. Mean flood depth (m) obtained from HEC-RAS (v5) 2D [30] for each of the land use polygons identified in Figure 5 for fluvial flooding and Combined (fluvial and pluvial) flooding.
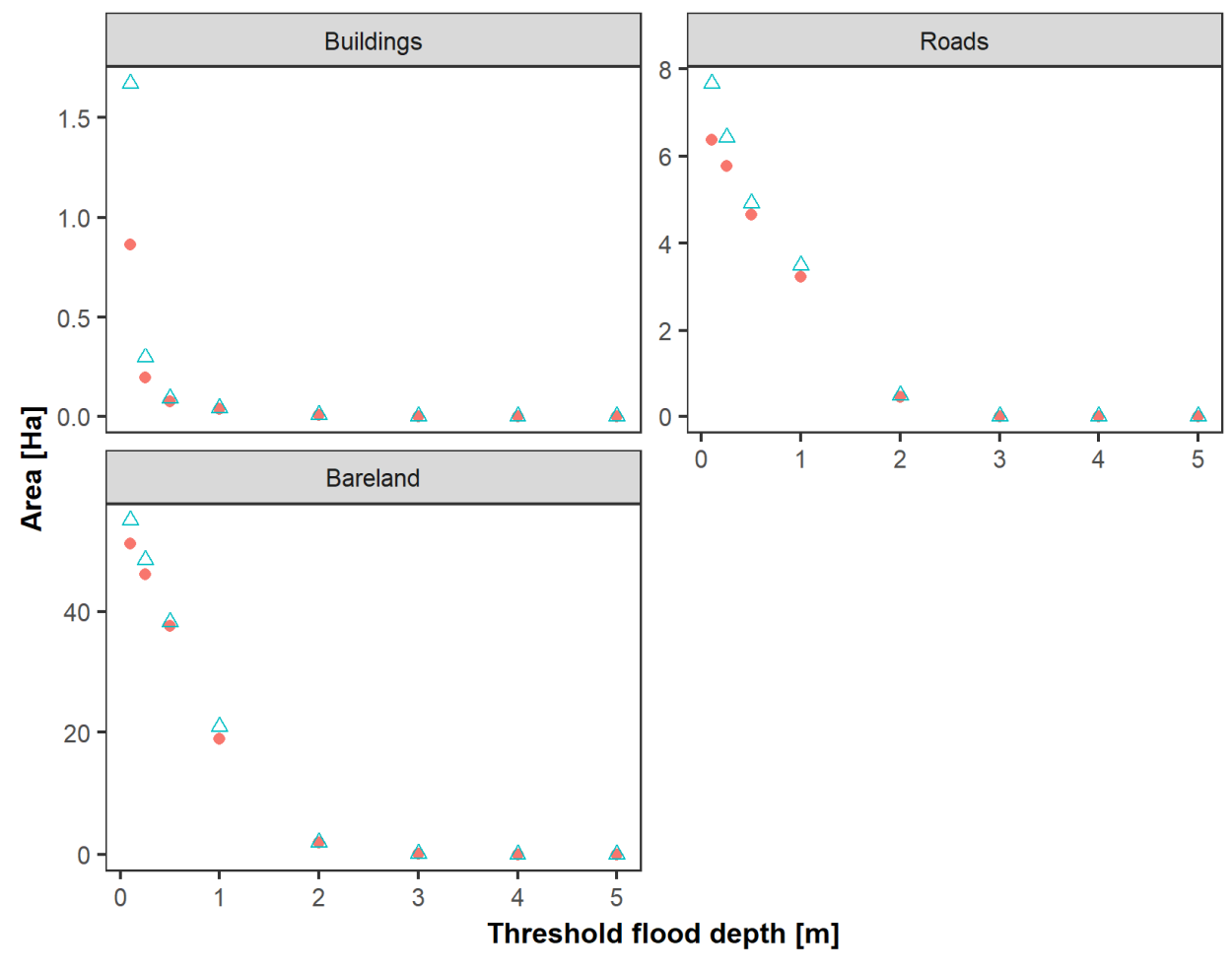

- Fluvial $\triangle$ Combined

Figure 7. Flooded area versus flood depth per land use type buildings and roads.

Table 3. Number of properties affected and contribution of pluvial flooding in total flood depth.

\begin{tabular}{cc}
\hline The Contribution of Pluvial Flooding in Total Flood Depth & Number of Properties \\
\hline 0 (Fluvial flooding only) & 16 \\
$(0 \%, 25 \%]$ & 84 \\
$(25 \%, 50 \%]$ & 41 \\
$(50 \%, 75 \%]$ & 11 \\
$(7 \%, 100 \%)$ & 10 \\
$100 \%$ (Pluvial flooding only) & 51 \\
\hline Total & 213 \\
\hline
\end{tabular}


The majority of the residential properties affected by the fluvial flooding are located in close proximity to the river. Since the pluvial flooding affected the entire area unlike the fluvial flooding, the number of properties that are affected by pluvial flooding only (51) is much higher than a number of properties that are affected by fluvial flooding only (16). However, this does not mean that pluvial flooding is the major cause of the damage as the flood depth associated with pluvial flooding in this instance is smaller than the fluvial levels.

\section{Discussion}

The potential for pluvial flooding to be a significant contributor to flood impacts during a flood event is often overlooked in a catchment like Cockermouth, which is historically known to be affected by fluvial flooding. However, the results presented here show that the damage caused by pluvial flooding is also significant. Although the flood depths associated with the pluvial flooding, in this case, are less than those associated with the fluvial flooding, a large proportion of the affected area was impacted by pluvial flooding resulting in significant damage.

The model used here to generate fluvial and pluvial flooding estimates produced flood extents that are consistent with those reported by the EA in respect of the flood event which took place from $04 / 12 / 15$ to $08 / 12 / 15$. The model error is less than $6 \%$ for the peak water levels observed during storm Desmond. Peak water levels in river channels are key to understanding and estimating the flood extents and impacts of fluvial events as they are an indicator of whether or not flood defence structures will be over-topped. They were, therefore, the main focus of this study. Very little information exists yet on the validation/accuracy of pluvial flooding predictions due to the difficulties in collecting data of its impact and extent during and after events. This makes it difficult to calibrate the flood water levels outside the river. In this study, validation of the properties affected by the pluvial flooding was not possible as no data was available for that purpose. Data available through the Environment Agency included properties affected by flooding from all sources but did not discriminate between fluvial and pluvial impacts. Some home owners affected by pluvial flooding are reluctant to report it as this may have an impact on the value of their property. However, through the use of UAS systems, it may be possible in future to calibrate pluvial flood extents including depth information. This is one of the potential applications and extension of this study.

The effect of variations in micro-topography as a result of either coarser resolution or a temporal change in the DEM on the prediction of flood extent and impact has been reported previously by other authors [20-22]. Micro-topography effects could be identified in the future using high resolution imagery collected from UASs. [51] showed that it is possible to obtain high-resolution DSMs from UAS photogrammetry for urban areas with an RMSE in elevation of around $3 \mathrm{~cm}$. Similarly, in [52] the authors found that UAS DEMs performed competitively in comparison to traditional LiDAR-based DEM in urban areas, whereas [53] reported centimetre-level accuracy when using a GCP-free RTK airborne UAS approach. However, detailed topographical characterization of such structures may require sensors (LiDAR) able to generate more accurate DEMs than those obtained from RGB cameras. With the increased availability of high accuracy DEM, 2D flood inundation modelling is becoming less challenging but computationally more demanding than it used to be. In addition to a high-resolution DEM, properly calibrated water levels are another main requirement of 2D flood inundation modelling. In this study, freely available high-resolution DSM and DTM were combined to generate the final DEM used for the modelling. However, there are still some challenges that need to be addressed. One of the main challenges is how best to represent the drainage network in the model. Although open drainage can be represented in a DEM, the closed network cannot be represented. HEC-RAS 2D is capable of simulating some of the drainage structures (e.g., culverts). It is also possible to use models with 1D-2D coupling [50]. However, such a complicated model needs complete drainage network data which is not available for Cockermouth. Such data collection will possibly require a ground-based survey which will be costly. Hence, as a simpler solution due to the lack of data, a rainfall reduction of 
$12 \mathrm{~mm} \mathrm{hr}^{-1}$ was applied in this study to represent the effects of the drainage system as recommended in $[54,55]$.

In the absence of measured boundary conditions, they were estimated using water gauge data measured within the catchment. This is one of the major challenges associated with ungauged/sparsely gauged catchments where the boundary conditions need to be estimated using measured data or using data from a similar catchment [13]. In such catchments, it is not always possible to obtain a good calibration. However, in this case, the peak water levels were calibrated with $<6 \%$ of error. Our major aim was to calibrate the peak water levels in order to obtain the maximum flood extent and maximum flood depths accurately.

Historically, Cockermouth was considered to be mainly affected by fluvial flooding. However, as reported in [13] and in the present study, there were many areas in Cockermouth that were affected by pluvial as well as fluvial flooding. Future flood risk management plans should consider the various sources of flooding within an area so that more effective risk reduction measures can be developed and implemented. Based on the flood modelling results presented here of the 213 residential buildings flooded 51 were due to pluvial sources alone. In addition, pluvial flooding increased the flood depths in 146 of the properties that were identified as being affected by fluvial flooding. In some cases, the pluvial flooding comprised $50 \%$ of the overall flood depth. The methodology presented here could help improve current approaches to estimating the numbers of properties affected by a flood event, thereby informing and improving flood risk management decisions and emergency response planning.

\section{Conclusions}

In this study, we presented a remote sensing based integrated methodology in order to enhance current practice in the estimation of flood extent and damage, and to characterise the spatial distribution of pluvial and fluvial flooding using a high-resolution DEM. First, a DEM based 2D model was developed to compare the fluvial and combined pluvial and fluvial flood damage areas for different land use types. We also compared the number of residential properties affected by fluvial and combined flooding using a combination of modelled results and UAS data. Cockermouth, a town which has experienced multiple flood events over the last decade, was selected as a study site. As far as the authors are aware, this is the first time remote sensing data, hydrological modelling and flood damage at property level have been combined to differentiate between the flood extents and damage caused by fluvial and pluvial flooding in the same event.

Results show that the contribution of pluvial flooding should not be ignored even in a catchment where pluvial flooding is the major cause of the flood damages. Although the flood depths caused by pluvial flooding were found to be lower than the fluvial flood depths, the affected area is still significant. Half of the building area $(\sim 0.8 \mathrm{ha})$ that is flooded up to $0.1 \mathrm{~m}$ is due to the addition of pluvial flooding whilst more than 1 ha of the road area is flooded up to $0.1 \mathrm{~m}$ due to the addition of pluvial flooding. Pluvial flooding also increased the flooded area of the bare land by $\sim 4$ ha and identifying these flooded bare land areas is important, for example, in the design of sustainable drainage systems (SuDS) and to inform planning decisions concerning the location of new houses. Among the 213 residential buildings that are affected, 51 building were affected by the addition of the pluvial flood. Not only does the pluvial flooding increases the affected properties, but it also increased the flood depths of the other 146 properties that were identified as affected by fluvial flooding, in some cases by more than $50 \%$. Hence, it may be that in certain instances it is the additional contribution from the pluvial flooding that takes the flood depth over a threshold level that results in a greater impact. These findings show the importance of taking pluvial flooding into consideration by, for example, emergency responders, urban planners and insurers. It highlights the need for pluvial flooding to have greater prominence in the development of flood risk management strategies and activities including appropriate budget allocations.

Most of the data used in this study was obtained via remote sensing methods, including UASs. This demonstrates that the much-improved remote sensing techniques that have become available 
over the last decade or so will enable a remote sensing based framework to be developed and enhance current practices in the estimation of flood extent and damage. In addition to the application of UAS data in this study, there is still a considerable potential to improve/and extend this work by using additional UAS data. This includes (a) validating pluvial model predictions using UAS data, (b) improving pluvial and fluvial model calibration using temporally collocated data derived from UASs (DSM, DEM, flood depths, water velocities) and (c) capturing temporal and spatial dynamics in the topography at a micro-topography level using UAS data. Such an improved remote sensing based methodology could readily be adapted at a reasonable cost to a new catchment, at least in countries where remote sensing data is freely available.

Author Contributions: Conceptualization, M.M. and M.R.C.; data curation, M.R.C. and M.M.; methodology, M.M. and M.R.C.; validation, M.M., M.R.C., G.S. and P.L.; writing—original draft preparation, M.M. and M.R.C.; writing-review and editing, M.R.C., M.M., G.S., P.L. and T.I.; supervision, M.R.C. and P.L.; administration and funding acquisition, M.R.C. and P.L.

Funding: This research was funded by the Natural Environment Research Council, grant numbers NE/N020316/1 and NE/P018890/1 and the Engineering and Physical Sciences Research Council, grant "Impact Acceleration Award" and grant number EP/P02839X/1 (Emergency flood planning and management using unmanned aircraft systems). The APC was funded by the UK Research and Innovation block grant through Cranfield University.

Acknowledgments: We would like to thank NERC and EPSRC for funding this research under research grants NERC Drone Watch NE/N020316/1, NERC Pathfinder NE/P018890/1, EPSRC Impact Acceleration Award and EPSRC EP/P02839X/1-Emergency flood planning and management using unmanned aircraft systems. We would also like to thank the Environment Agency and Caintech Ltd. for providing support at specific stages of the project. The underlying data is confidential and cannot be shared. Special thanks go to the reviewers for their useful and constructive comments that helped improve the overall quality of the manuscript.

Conflicts of Interest: The authors declare no conflict of interest. The funders had no role in the design of the study; in the collection, analyses, or interpretation of data; in the writing of the manuscript, or in the decision to publish the results.

\section{References}

1. Environment Agency. Flooding in England: A National Assessment of Flood Risk; Environment Agency: Bristol, UK, 2009; Volume 36.

2. Sterna, L. Pluvial Flood Damage Modelling-Assessment of the Flood Damage Model HOWAD-PREVENT; Delft University of Technology: Delft, The Netherlands, 2012.

3. Houston, D.; Werritty, A.; Bassett, D. Pluvial (Rain-Related) Flooding in Urban Areas: The Invisible Hazard; University of Glasgow: Glasgow, UK, 2011.

4. Bowker, P. Flood Resistance and Resilience Solutions: An R E D Scoping Study; Food and Rural Affairs: London, UK, 2007.

5. Penning-Rowsell, E.; Priest, S.; Parker, D.; Morris, J.; Tunstall, S.; Viavattene, C.; Chatterton, J.; Owen, D. MCM-Online I The Handbook; Routledge: Abingdon, UK, 2016.

6. Penning-Rowsell, E.; Priest, S.; Parker, D.; Morris, J.; Tunstall, S.; Viavattene, C.; Chatterton, J.; Owen, D. MCM-Online I The Manual; Routledge: Abingdon, UK, 2013.

7. Penning-Rowsell, E.C. A realistic assessment of fluvial and coastal flood risk in England and Wales. Trans. Inst. Br. Geogr. 2015, 40, 44-61. [CrossRef]

8. Arnell, N.W.; Gosling, S.N. The impacts of climate change on river flood risk at the global scale. Clim. Change 2016, 134, 387-401. [CrossRef]

9. Speight, L.J.; Hall, J.W.; Kilsby, C.G. A multi-scale framework for flood risk analysis at spatially distributed locations. J. Flood Risk Manag. 2017, 10, 124-137. [CrossRef]

10. Zhou, Q.; Mikkelsen, P.S.; Halsnæs, K.; Arnbjerg-Nielsen, K. Framework for economic pluvial flood risk assessment considering climate change effects and adaptation benefits. J. Hydrol. 2012, 414-415, 539-549. [CrossRef]

11. Douglas, I.; Garvin, S.; Lawson, N.; Richards, J.; Tippett, J.; White, I. Urban pluvial flooding: A qualitative case study of cause, effect and nonstructural mitigation. J. Flood Risk Manag. 2010, 3, 112-125. [CrossRef]

12. Olsen, S.A.; Zhou, Q.; Linde, J.J.; Arnbjerg-Nielsen, K. Comparing Methods of Calculating Expected Annual Damage in Urban Pluvial Flood Risk Assessments. Water 2015, 7, 255-270. [CrossRef] 
13. Rivas Casado, M.; Irvine, T.; Johnson, S.; Palma, M.; Leinster, P. The Use of Unmanned Aerial Vehicles to Estimate Direct Tangible Losses to Residential Properties from Flood Events: A Case Study of Cockermouth Following the Desmond Storm. Remote Sens. 2018, 10, 1548. [CrossRef]

14. Mark, O.; Weesakul, S.; Apirumanekul, C.; Aroonnet, S.B.; Djordjević, S. Potential and limitations of 1D modelling of urban flooding. J. Hydrol. 2004, 299, 284-299. [CrossRef]

15. Asselman, N.E.M.; van Wijngaarden, M. Development and application of a 1D floodplain sedimentation model for the River Rhine in The Netherlands. J. Hydrol. 2002, 268, 127-142. [CrossRef]

16. Cobby, D.M.; Mason, D.C.; Davenport, I.J. Image processing of airborne scanning laser altimetry data for improved river flood modelling. ISPRS J. Photogramm. Remote Sens. 2001, 56, 121-138. [CrossRef]

17. Chen, A.S.; Evans, B.; Djordjević, S.; Savić, D.A. A coarse-grid approach to representing building blockage effects in 2D urban flood modelling. J. Hydrol. 2012, 426-427, 1-16. [CrossRef]

18. Vojinovic, Z.; Tutulic, D. On the use of 1D and coupled 1D-2D modelling approaches for assessment of flood damage in urban areas. Urban Water J. 2009, 6, 183-199. [CrossRef]

19. Leandro, J.; Chen, A.S.; Djordjević, S.; Savić, D.A. Comparison of 1D/1D and 1D/2D Coupled (Sewer/Surface) Hydraulic Models for Urban Flood Simulation. J. Hydraul. Eng. 2009, 135, 495-504. [CrossRef]

20. Saksena, S.; Merwade, V. Incorporating the effect of DEM resolution and accuracy for improved flood inundation mapping. J. Hydrol. 2015, 530, 180-194. [CrossRef]

21. Vaze, J.; Teng, J.; Spencer, G. Impact of DEM accuracy and resolution on topographic indices. Environ. Model. Softw. 2010, 25, 1086-1098. [CrossRef]

22. Ogania, J.L.; Puno, G.R.; Alivio, M.B.T.; Taylaran, J.M.G. Effect of digital elevation model's resolution in producing flood hazard maps. Glob. J. Environ. Sci. Manag. 2019, 5, 95-106.

23. Bates, P.D. Integrating remote sensing data with flood inundation models: how far have we got? Hydrol. Process. 2012, 26, 2515-2521. [CrossRef]

24. Rigelsford, J. Remote Sensing in Hydrology and Water Management. Sens. Rev. 2001, 21, ii-ii(1). [CrossRef]

25. Kheder, D.K. Application of Remote Sensing and GIS for Flood Risk Assessment: A case study of Al Kharj Valley Saudi Arabia. Int. J. Sci. Eng. Res. 2014, 5, 110-115.

26. Chen, B.; Krajewski, W.F.; Goska, R.; Young, N. Using LiDAR surveys to document floods: A case study of the 2008 Iowa flood. J. Hydrol. 2017, 553, 338-349. [CrossRef]

27. Ettritch, G.; Hardy, A.; Bojang, L.; Cross, D.; Bunting, P.; Brewer, P. Enhancing digital elevation models for hydraulic modelling using flood frequency detection. Remote Sens. Environ. 2018, 217, 506-522. [CrossRef]

28. dhi MIKE. Available online: https:/ / www.mikepoweredbydhi.com/ (accessed on 16 December 2018).

29. innovyze InfoWorks. Available online: http://www.innovyze.com/products/infoworks_icm/(accessed on 16 December 2018).

30. USACE HECRAS. Available online: http://www.hec.usace.army.mil/software/hec-ras/ (accessed on 16 December 2018).

31. Oliver, G.; Tim, A. Surface Water Flooding Hazard Impact Model Impact Library Refinement and Testing: Phase 2 Report; 2016, Volume 44. Available online: http:/ /www.naturalhazardspartnership.org.uk/wp-content/ uploads /2016/10/Surface-Water-Flooding-Hazard-Impact-Model-Impact-Library-Development_2.0.pdf (accessed on 9 March 2019).

32. Visser, F. The Day Roads Became Rivers: A GIS-Based Assessment of Flash Floods in Worcester. In Flood Risk Management: Research and Practice; Huntington, S., Samuels, P., Allsop, W., Harrop, J., Eds.; CRC Press: London, UK, 2008; pp. 1617-1621.

33. Visser, F. Rapid mapping of urban development from historic Ordnance Survey maps: An application for pluvial flood risk in Worcester. J. Maps 2014, 10, 276-288. [CrossRef]

34. Office for National Statistics Local statistics-Office for National Statistics. Available online: https:/ / www. ons.gov.uk/help/localstatistics (accessed on 16 November 2018).

35. Met Office UK STORM CENTRE. Available online: https://www.metoffice.gov.uk/barometer/uk-stormcentre (accessed on 16 November 2018).

36. McCall, I.; Evans, C. Flood Investigation Report; Environment Agency: Bristol, UK; Cumbria County Council: Cumbria, UK, 2016.

37. The National River Flow Archive 75003-Derwent at Ouse Bridge. Available online: https://nrfa.ceh.ac.uk/ data/station/info/75003 (accessed on 3 January 2019). 
38. The National River Flow Archive 75004-Cocker at Southwaite Bridge. Available online: https://nrfa.ceh. ac.uk/data/station/info/75004 (accessed on 3 January 2019).

39. MetOffice UK Storm Desmond. Available online: https://www.metoffice.gov.uk/barometer/uk-stormcentre/storm-desmond (accessed on 17 December 2018).

40. Gaugemap Kingfisher Cockermouth. Available online: https://www.gaugemap.co.uk/\#!Detail/649 (accessed on 4 January 2019).

41. Gaugemap South Street Footbridge. Available online: https://www.gaugemap.co.uk/\#!Detail/648 (accessed on 4 January 2019).

42. UK Civil Aviation Authority—Safety and Airspace Regulation Group. CAP722: Unmanned Aircraft System Operations in UK Airspace-Guidance; UK Civil Aviation Authority: London, UK, 2015.

43. UK Civil Aviation Authority-The Office of the General Counsel. CAP 393: The Air Navigation Order 2016 and Regulations; UK Civil Aviation Authority: London, UK, 2018.

44. Aviation Weather Centre METAR Data. Available online: https://www.aviationweather.gov/metar/data? ids $=$ EGOM\&format $=$ decoded $\&$ hours $=36 \&$ taf $=$ on\&layout $=$ on $\&$ date $=0$ (accessed on 4 January 2019).

45. Environment Agency. Available online: https://data.gov.uk/dataset/80c522cc-e0bf-4466-840957a04c456197/lidar-composite-dsm-1m (accessed on 25 July 2018).

46. Patel, D.P.; Ramirez, J.A.; Srivastava, P.K.; Bray, M.; Han, D. Assessment of flood inundation mapping of Surat city by coupled 1D/2D hydrodynamic modeling: A case application of the new HEC-RAS 5. Nat. Hazards 2017, 89, 93-130. [CrossRef]

47. Moya Quiroga, V.; Kure, S.; Udo, K.; Mano, A. Application of 2D numerical simulation for the analysis of the February 2014 Bolivian Amazonia flood: Application of the new HEC-RAS version 5. RIBAGUA Rev. Iberoam. del Agua 2016, 3, 25-33. [CrossRef]

48. Pasquier, U.; He, Y.; Hooton, S.; Goulden, M.; Hiscock, K.M. An integrated 1D-2D hydraulic modelling approach to assess the sensitivity of a coastal region to compound flooding hazard under climate change. Nat. Hazards 2018, 94, 1-23. [CrossRef]

49. U.S. Army Corps of Engineering. HEC-RAS 5.0 Hydraulic Reference Manual; U.S. Army Corps of Engineers, Institute for Water Resources, Hydrologic Engineering Center: Davis, CA, USA, 2016; ISBN CPD-68.

50. Environment Agency. What Is the Updated Flood Map for Surface Water? Environment Agency: Bristol, UK, 2013.

51. Forlani, G.; Dall'Asta, E.; Diotri, F.; di Cella, U.M.; Roncella, R.; Santise, M. Quality assessment of DSMs produced from UAV flights georeferenced with on-board RTK positioning. Remote Sens. 2018, 10, 311. [CrossRef]

52. Leitão, J.P.; Moy De Vitry, M.; Scheidegger, A.; Rieckermann, J. Assessing the quality of digital elevation models obtained from mini unmanned aerial vehicles for overland flow modelling in urban areas. Hydrol. Earth Syst. Sci. 2016, 20, 1637-1653. [CrossRef]

53. Yeh, M.L.; Chou, Y.T.; Yang, L.S. The evaluation of GPS techniques for UAV-based Photogrammetry in Urban Area. Int. Arch. Photogramm. Remote Sens. Spat. Inf. Sci. ISPRS Arch. 2016, 41, 1079-1084. [CrossRef]

54. Moramarco, T.; Melone, F.; Singh, V.P. Assessment of flooding in urbanized ungauged basins: a case study in the Upper Tiber area, Italy. Hydrol. Process. 2005, 19, 1909-1924. [CrossRef]

55. Grimaldi, S.; Petroselli, A.; Arcangeletti, E.; Nardi, F. Flood mapping in ungauged basins using fully continuous hydrologic-hydraulic modeling. J. Hydrol. 2013, 487, 39-47. [CrossRef]

(C) 2019 by the authors. Licensee MDPI, Basel, Switzerland. This article is an open access article distributed under the terms and conditions of the Creative Commons Attribution (CC BY) license (http://creativecommons.org/licenses/by/4.0/). 